\title{
POPULATION STRUCTURE AND SOCIAL ORGANIZATION IN THE PRIMITIVE ANT AMBLYOPONE PALLIPES \\ (HYMENOPTERA: FORMICIDAE)
}

\author{
By James F. A. Traniello ${ }^{1}$ \\ Harvard University, \\ Museum of Comparative Zoology Laboratories \\ Cambridge, Massachusetts 02138, U.S.A.
}

\section{IINTRODUCTION}

The genus Amblyopone contains the most morphologically and behaviorally primitive species in the poneroid complex of ants, and a detailed examination of their social structure could significantly contribute to the reconstruction of social evolution in the Formicidae. But because of their cryptic habits and distribution, the biology of the majority of species of Amblyopone and the related genera Mystrium, Myopopone, Prionopelta, and Onychomyrmex remains almost entirely unknown. Previous investigations have provided information on colony foundation (Haskins, 1928; Haskins and Enzmann, 1938; Haskins and Haskins, 1951), ecology, behavior, and taxonomy (Wheeler, 1900; Brown, 1960; Gotwald and Levieux, 1972; Baroni Urbani, 1978), and physiology (Whelden, 1958). Still, many of the details of social organization in Amblyopone are lacking. I present in this paper the results of a two-year study on the behavior and ecology of Amblyopone pallipes.

\section{Material AND Methods}

Study areas and nest collection

Thirty-one colonies of $A$. pallipes were collected under stones in a damp, white pine woodland in Westford, Massachusetts. A single colony was taken under the bark of a rotting log. Nests generally consisted of one or two shallow $(6-10 \mathrm{~mm})$ depressions in the soil immediately beneath the stone, from which a single gallery opened to subterranean chambers. Gentle excavation usually revealed one or two additional loosely structured chambers. Workers, queens,

'Present address: Department of Biology, Boston University, Boston, Massachusetts 02215

Manuscript received by the editor February' 18, 1982. 
sexuals, and brood were found at all levels of the nest and were quickly aspirated.

Distribution and natural history

A. pallipes has been found in the eastern United States and in the St. Lawrence Valley in Canada in cool, moist, forested areas (Brown, 1960). General references on the natural history of this species are given by Wheeler (1900) and Haskins (1928).

\section{Laboratory arrangements}

Colonies were housed in artificial nests composed of a thick, moist filter paper bottom with cotton sides approximately $6 \mathrm{~mm}$ high covered with a glass plate. The nests were placed in $15 \times 22 \mathrm{~cm}$ plastic boxes in which the humidity was kept high. The total nest area was roughly $10 \mathrm{~cm}^{2}$. A second chamber, similar in structure but somewhat larger, was connected to the nest as a foraging arena, where live prey were offered. Colonies were fed on whole, live geophilomorph and lithobiid centipedes; in addition, elatyrid, buprestid, and tenebrionid beetle larvae were acceptable to the ants. This method of culture proved successful and greatly facilitated studies of social interaction since the activity of an entire colony could be monitored on the stage of a dissecting microscope. Ethogram data were compiled in this manner, and were analyzed using the methods of Fagen and Goldman (1977).

\section{Results AND Discussion}

1. Life cycle and population structure.

Nest distribution and colony size. The spatial distribution of colonies at the principal study site in Westford is presented in Fig. 1. An interesting feature of this population, in addition to its clumped distribution pattern is that three colonies were collected under stones in 1978 precisely where colonies were found the year before. This suggests that the colonies that were collected represented subunits of a large, subterranean population. Each unit is small (modal size class $=9-16$ workers). Complete collection data are presented in Fig. 2. Although distributional data are not given, a population of seemingly comparable density was discovered by Wheeler (1900), who uncovered 30 nests in a three hour period. Also, the colony size data correspond closely to the data of Francoeur $(1965,1979$, and personal communication). 


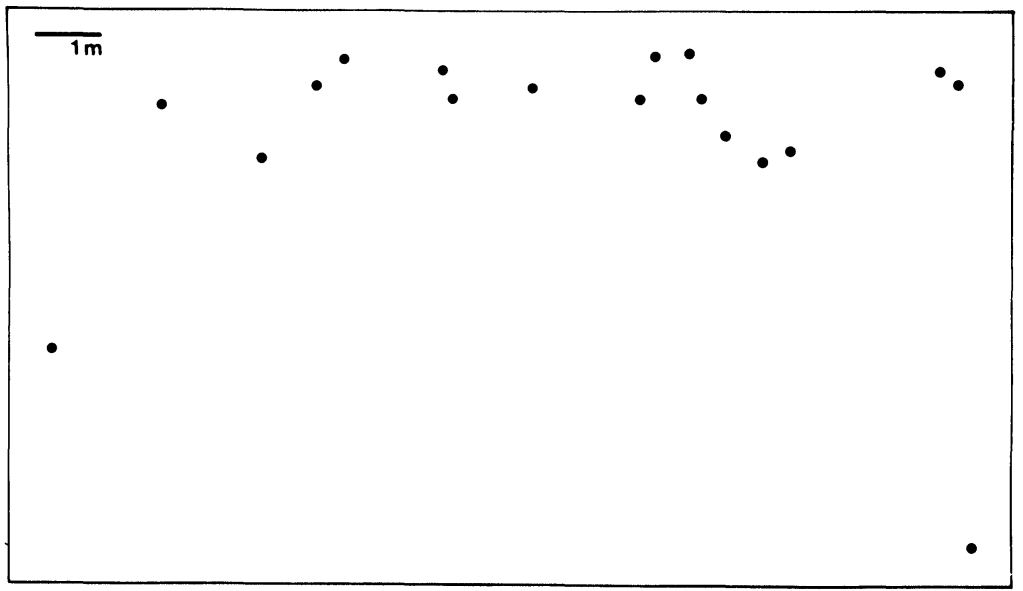

Fig. 1. - The spatial distribution of nests at the principal study site.

Queen number. The frequency distribution of the number of queens in a colony is given in Fig. 3. Of 19 queenright colonies, 10 (52\%) contained more than one dealate female. Observations of multiple queened colonies in the laboratory revealed that in at least some of these colonies each queen was functionally reproductive. However, many queens in apparently polygynous colonies did not lay eggs, and engaged primarily in worker tasks.

Life cycle, colony reproduction, and population structure. Because colonies were collected and censused throughout the spring and summer of 1977 and 1978, it is possible to outline the life cycle of $A$. pallipes (Fig. 4). Eggs are laid in late April or early May and larvae hatch and develop throughout June and July. Mature larvae pupate in mid-July and early August, and adults eclose approximately two to three weeks later. Although small numbers of eggs and larvae are present in most colonies throughout the spring and summer, it appears that only one brood matures per year. The large number of eggs found in colonies collected in August hatch before September and overwinter as larvae (Talbot, 1957). It is possible that the winter chilling results in the determination of these larvae as sexuals. In late August and early September workers and sexuals simultaneously eclose unassisted from their pupal cases. The adults which eclose at this time are predominantly workers. In four colo- 


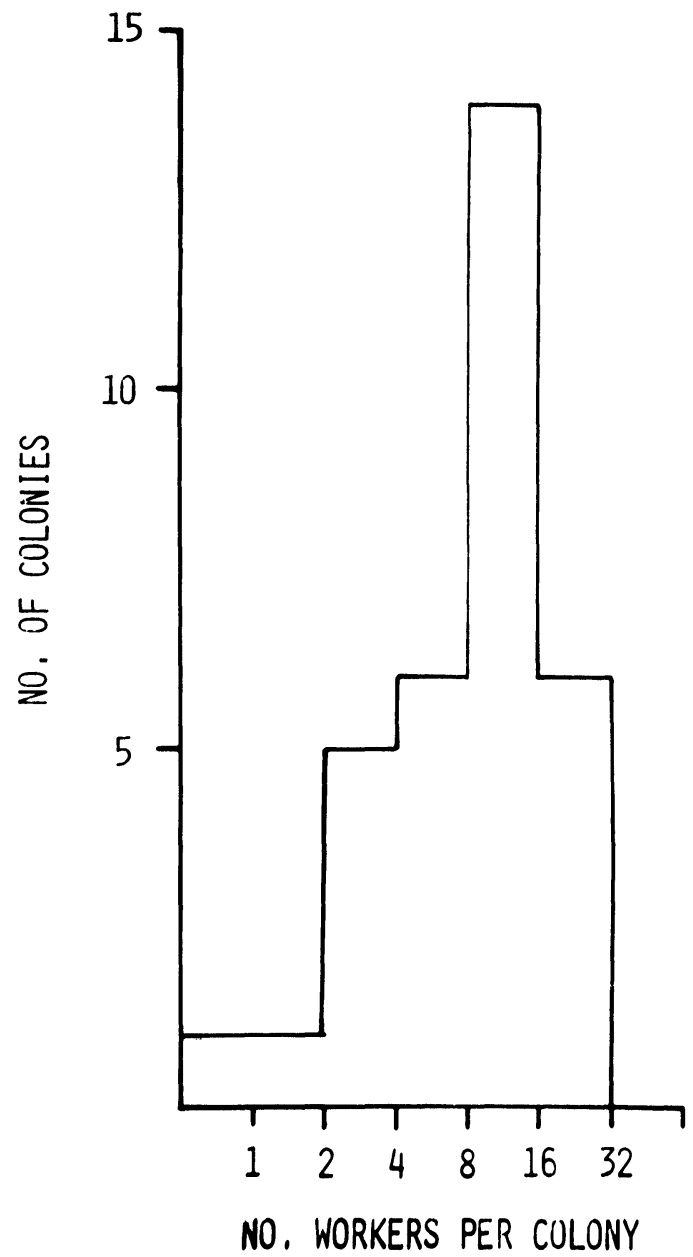

Fig. 2. - Frequency distribution of colony sizes for 35 nests.

nies collected in late August which reared brood in the laboratory,

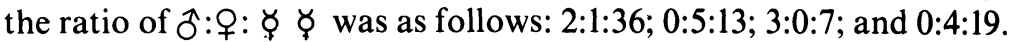
In all cases the worker population of a colony was at a maximum at this time. If this is considered in conjunction with the available information on nuptial flights in $A$. pallipes, then it is possible to speculate on colony reproduction and population structure. 


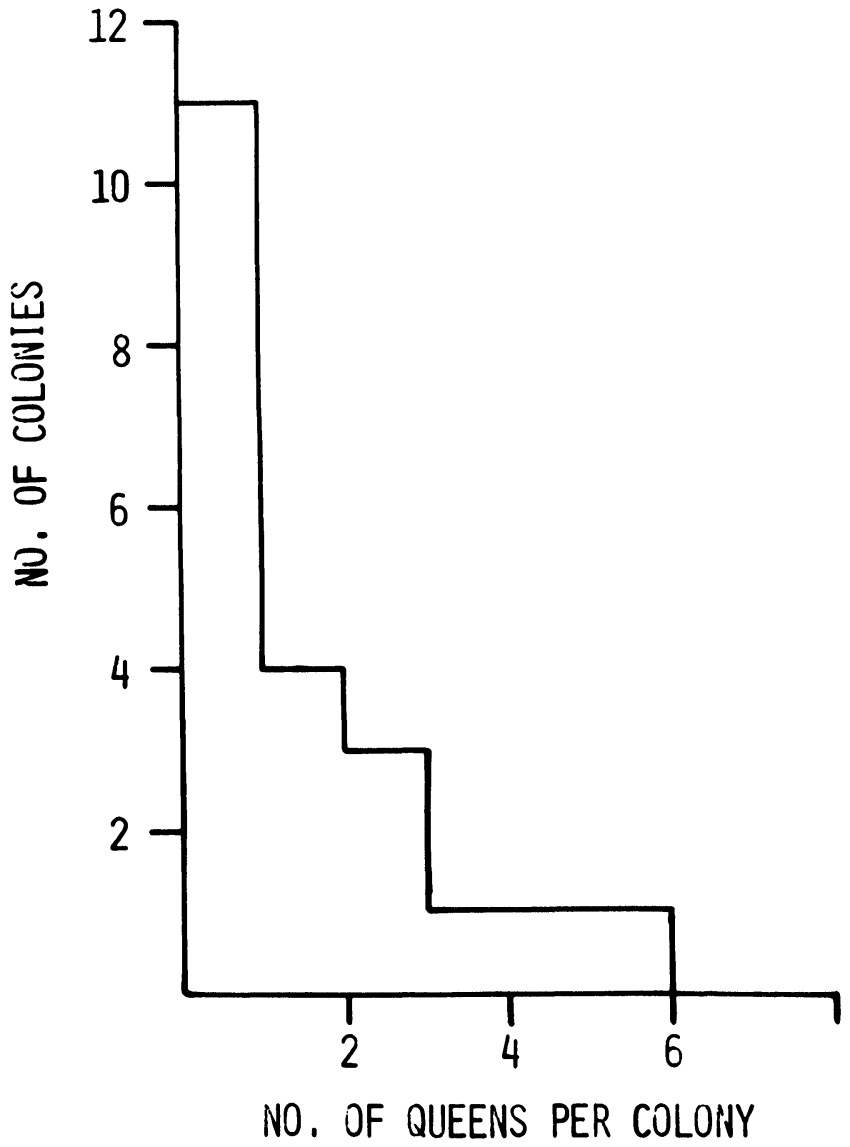

Fig. 3. - Frequency distribution of the number of dealate females in 19 queenright colonies.

Although the complete sequence of colony reproduction has not been observed, the studies of Haskins $(1928,1979)$ and Haskins and Enzmann (1938) provide some evidence of its organization. Early in September, winged females leave the nest and disperse over short distances, finally alighting on the ground or low vegetation. Then, with gaster arched and sting partially extruded, they "call" males with a chemical sexual attractant. Males quickly locate females, copulation ensues, and soon after insemination females shed their wings and re-enter the soil; perhaps they return to the parent nest. 
At this point in the life cycle, the worker/queen ratio is highest, as described above, yet colonies collected in the late spring are much smaller in size (approximately 50\%). Therefore, colony reproduction by budding may occur if one or more fecundated queens depart with a portion of the worker force. This hypothesis has previously been considered by Wheeler (1900) and Brown (1960), and is supported by my data on colony growth, nest distribution, and nest structure. An additional feature of the nest distribution pattern supports the hypothesis of limited dispersal. The most dense population of colonies occurred on the south side of an early stone wall $(<1 \mathrm{~m}$ high), although nest sites were abundant on both the north and south sides, and soil, vegetational, and exposure parameters appeared to be identical. Also, laboratory observations indicate that alate females may shed their wings before mating occurs. On several occasions newly eclosed females left the nest, shed their wings, and returned to the nest. Because mating occurs on the ground, such behavior does not exclude the possibility that these individuals could eventually become inseminated. These females may then return to the parent nest or may be adopted by a nearby colony. In several laboratory experiments queens were introduced into other queenright nests or orphaned colonies. In all cases they were accepted by both workers and queens. Similarly, workers could be transferred from one colony to another without aggression. Therefore, populations of $A$. pallipes appear to be unicolonial and secondarily polygynous. Ecologically, the patchy distribution of this ant correlates with this type of population structure.

\section{Social organization}

The social ethogram. Social ethogram data were gathered from five colonies which were observed for a total of 73 hours, during which 6,500 individual acts were recorded. The behavioral catalog of a single colony of $A$. pallipes ( 2 queens, 18 workers, brood) that was studied for 25.7 hours is given in Table $\mathbf{l}$. The total number of acts observed was 42 (95\% confidence interval for catalog size [27, 47]), and the sample coverage was 0.9992 . Behaviors listed in the ethogram having a frequency of 0 were observed in other colonies and are included as part of the species repertory. The majority of activities are common to many ant species; those that are unusual will be discussed briefly. Antennal tipping is a behavior previously described in Zacryptocerus varians (Wilson, 1975) which occurred 

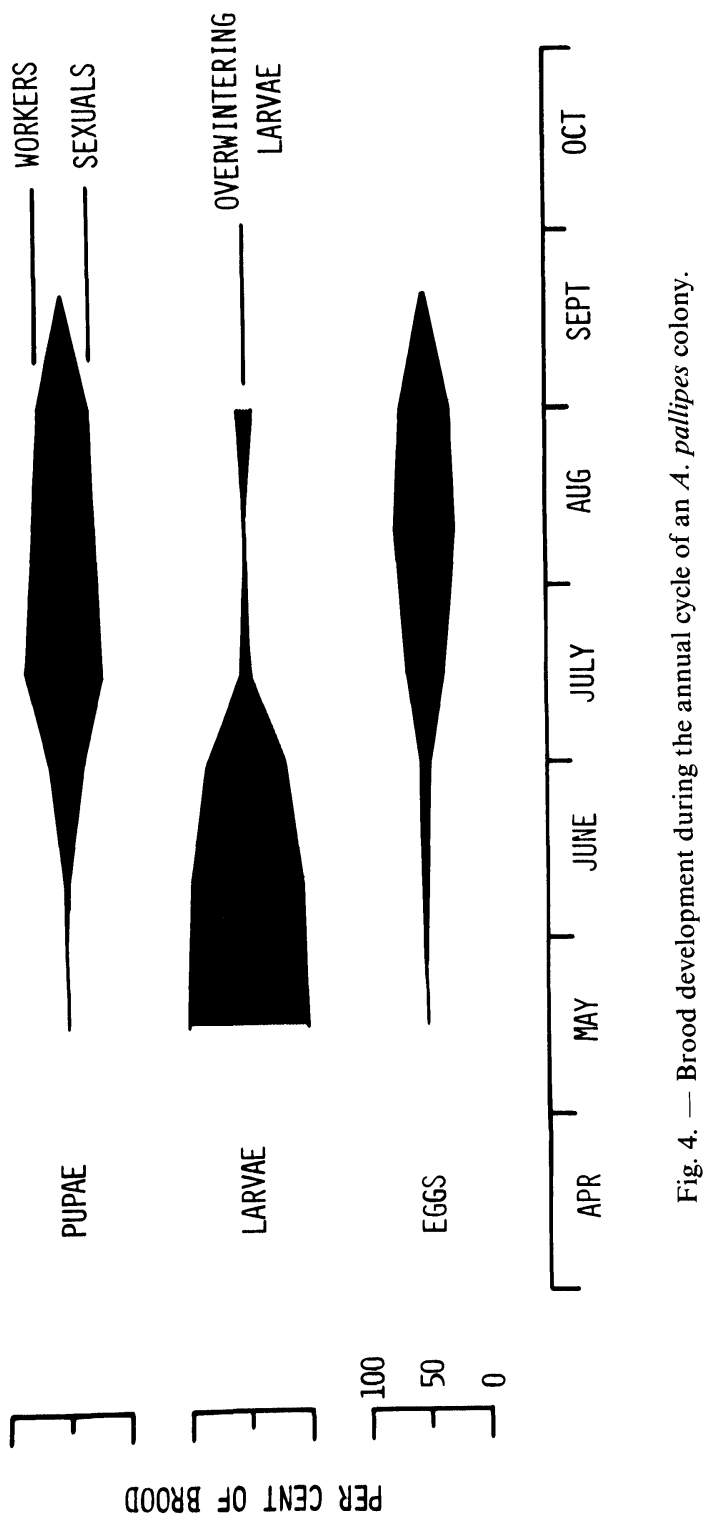
Table I. - The social ethogram. N= number of acts observed in each caste.

\begin{tabular}{|c|c|c|}
\hline Behavioral Act & $\begin{array}{l}\text { Workers }(16) \\
\mathrm{N}=2525\end{array}$ & $\begin{array}{l}\text { Queens (2) } \\
\mathrm{N}=158\end{array}$ \\
\hline 1. Self-groom & 0.3303 & 0.4114 \\
\hline 2. Allogroom queen & 0.0044 & 0 \\
\hline $\begin{array}{l}\text { 3. Allogroom worker } \\
\text { Brood care: }\end{array}$ & 0.0384 & 0 \\
\hline 4. Lay egg & 0 & 0.0127 \\
\hline 5. Carry egg or egg pile & 0.0123 & 0.0696 \\
\hline 6. Lick egg & 0.0305 & 0.1013 \\
\hline 7. Lick larva & 0.0950 & 0.1139 \\
\hline 8. Carry, drag, or role larva & 0.0337 & 0.0633 \\
\hline 9. Bank mature larva with soil & 0.0048 & 0 \\
\hline 10. Carry pupa & 0.1200 & 0 \\
\hline 11. Lick pupa & 0.0824 & 0.0127 \\
\hline 12. Place larvae on prey & 0.0032 & 0 \\
\hline 13. Assist removal of meconium & 0.0004 & 0 \\
\hline 14. Assist larval molt & 0.0012 & 0 \\
\hline $\begin{array}{l}\text { 15. Lick ecdysial skin } \\
\text { Aggressive display: }\end{array}$ & 0.0063 & 0.0380 \\
\hline 16. Undirected & 0.0250 & 0 \\
\hline 17. To worker & 0.0051 & 0.0127 \\
\hline 18. To queen & 0.0004 & 0 \\
\hline Predatory behavior: & & \\
\hline 19. Forage & 0.0158 & 0 \\
\hline 20. Sting prey & 0.0040 & 0 \\
\hline 21. Drag prey to nest & 0.0019 & 0 \\
\hline 22. Drag prey within nest & 0.0048 & 0 \\
\hline 23. Lick prey & 0.0578 & 0 \\
\hline $\begin{array}{l}\text { 24. Handle prey within nest } \\
\text { Nest maintenance and defense: }\end{array}$ & 0.0051 & 0 \\
\hline 25. Guard & 0.0083 & 0 \\
\hline 26. Handle nest material & 0.0190 & 0 \\
\hline 27. Repair nest wall & 0.0277 & 0 \\
\hline 28. Lick nest material & 0.0012 & 0 \\
\hline 29. Excavate nest & 0.0111 & 0 \\
\hline 30. Bury noxious object & 0.0004 & 0 \\
\hline 31. Carry or drag dead worker & 0 & 0 \\
\hline 32. Carry or drag live worker & 0.0004 & 0 \\
\hline 33. Extrude sting & 0.008 & 0.0190 \\
\hline 34. Remove empty pupal case & 0.0008 & 0 \\
\hline 35. Jitter & 0.0055 & 0.0190 \\
\hline 36. Jolt body & 0.0135 & 0.0633 \\
\hline 37. Lick meconium & 0.0008 & 0 \\
\hline 38. Tip antennae & 0.0008 & 0 \\
\hline 39. Flick antennae & 0.0099 & 0.0127 \\
\hline
\end{tabular}




\begin{tabular}{|c|c|c|}
\hline Behavioral Act & $\begin{array}{l}\text { Workers (16) } \\
\mathrm{N}=2525\end{array}$ & $\begin{array}{c}\text { Queens (2) } \\
\mathrm{N}=158\end{array}$ \\
\hline 40. Pinch larvae & 0 & 0.0063 \\
\hline 41. Cannibalize larva & 0.0170 & 0.0380 \\
\hline $\begin{array}{l}\text { 42. Discharge subpharyngeal } \\
\text { pellet }\end{array}$ & 0 & 0.0063 \\
\hline Totals: & 1.0 & 1.0 \\
\hline
\end{tabular}

infrequently in $A$. pallipes. During this behavior the body is raised, the gaster is curved forward, and with the mandibles agape the antennae are held forward with their terminal funicular segments slightly inclined toward each other. The significance of antennal tipping is unknown, but it appeared to be part of a grooming sequence. Vibrational displays were given by workers if the nest wall was breached or if an individual was mechanically disturbed. If the stimulus was intense enough, other workers would show the same vigorous jittering behavior, consisting of rapid vertical movements of the head and thorax. This behavior had the effect of producing a general arousal within the colony and resulted in an increase in the number of workers appearing at the source of stimulation. In the case of nest damage, building behavior eventually occurred but did not immediately follow. This signal appears to be a primitive form of mechanical communication, in which alarm is propagated directly through body contact. A similar vibratory display has been documented in A. australis (Hölldobler, 1977).

Workers and queens of $A$. pallipes have retained a number of behaviors that appear to reflect their wasp ancestry. Queens were seen grasping larvae and squeezing them in the neck region with their mandibles, thus causing them to regurgitate a droplet of clear liquid which they then consumed. Workers were never observed to regurgitate with other workers, queens, or larvae, and all individuals fed directly on prey. Aggression was observed between workers and queens. An aggressive display typically consisted of opening the mandibles and rising up on the extended legs. This behavior was usually exhibited by queens in the area of the egg pile and seemed to produce avoidance in contacted workers. These observations raise the question of whether queens maintain their reproductive status through behavioral dominance or inhibitory pheromones.

Polyethism. Studies on the division of labor within the worker caste have revealed that temporal castes are absent in the species. A 
complete account of polyethism in relation to the life history of $A$. pallipes is given by Traniello (1978).

Predatory behavior. Prey were found in only three of the colonies collected. In two colonies larvae were found clustered around lithobiid centipedes (length $=1.5-2.0 \mathrm{~cm}$ ), and in the third colony a carabid beetle larva was taken. In the laboratory, colonies were offered a variety of live arthropods that workers might encounter in leaf litter, soil, or rotting wood. Wood lice (Oniscus), house centipedes (Scutigera), and various millipedes were consistently rejected while small elatyrid, tenebrionid, and buprestid beetle larvae were carried to the nest and fed upon. The diet of $A$. pallipes appears to be restricted to live, linear-shaped arthropods that can be captured by workers. A related species, $A$. pluto, is entirely specialized on geophilomorph centipedes (Gotwald and Lévieux, 1972). When large, robust-bodied centipedes (Lithobius sp.) were offered to colonies of $A$. pallipes, workers were unable to grasp the prey due to its escape movements and body diameter. It is difficult to imagine a condition under which large prey could be captured, even if they were "cornered" in a narrow gallery. When Lithobius of similar size were held with forceps, workers were still unable to subdue the centipede. Freshly killed centipedes were not accepted. It is therefore difficult to support the hypothesis of a nomadic life style for $A$. pallipes. Although this species of Amblyoponini does not appear to move its colonies to the location of large, previously captured prey, other species, such as Onychomyrmex do provide evidence linking group predation and nomadism in this primitive group of ants (Wilson, 1958).

Prey capture and retrieval is very stereotyped, and solitary huntresses stalk prey in a highly methodical manner. As prey are approached, workers advance cautiously, apparently orienting to odors or air microcurrents produced by the prey. When within striking range $(2-3 \mathrm{~mm})$ the mandibles are opened and the head is oriented orthogonal to the long axis of the prey. Then in a single motion the mandibles close around the prey, the legs elevate the body, and the gaster is swung forward. The prey is then repeatedly stung and the venom soon shows its paralytic effects. Initially, only the area adjacent to the cuticle penetrated by the sting is immobilized, and stinging continues until escape movements stop. Subsequently, the retrieval of the prey begins after a brief period of self- 
grooming. The retrieval process varies in duration depending upon prey size, but even long $(4.0-5.0 \mathrm{~cm}, 2.0-2.5 \mathrm{~mm}$ in diameter) geophilomorph centipedes are easily dragged to the nest. A number of orientation trips made between the prey and the nest generally preceded retrieval. During these orientation runs, which were made throughout the retrieval process, workers continually checked their position relative to the nest. The prey was then dragged several centimeters; the worker then stopped, released the prey, and continued homeward until she contacted the nest entrance. She then returned to the prey and repeated this sequence, alternating prey movement with orientation trips. Once the prey was in the nest, other workers approached and began vigorously licking the areas of the prey's body opened during capture. Larvae were either carried to the prey or, if close enough, moved toward it and adjusted their position on its body on their own accord. At times workers assisted in positioning larvae. Additional details of feeding behavior are nearly identical to those described by Gotwald and Lévieux (1972).

Communication during foraging. At times, two or three ants attempted to jointly carry prey, but cooperative efforts were haphazard and inefficient. But cooperative retrieval seems unnecessary due to the physical capabilities of individual ants. The critical element in prey capture is probably not retrieving, but subduing relatively large arthropods. Often after a worker began stinging a prey item, a second or third worker approached and assisted in paralyzing the prey. The fact that workers were attracted to the point of prey capture suggested that additional ants may be recruited over short distances by orienting to prey odor, air currents, or some signal produced by the forager. To test the hypothesis that pheromones are involved in this process I stimulated foragers to grasp and attempt to sting the tip of a pair of forceps and then lowered the worker, still attacking the forceps tip, in front of the nest entrance. The response of workers in the nest was dramatic. In five replicates, $5.8 \pm 2.3$ workers $/ 0.5 \mathrm{~min}$ approached the nest entrance under the experimental conditions. Only $0.2 \pm 0.1$ workers $/ 0.5 \mathrm{~min}$ were attracted to the nest entrance in controls (agitated forceps alone). This difference is statistically significant $(.001<\mathrm{p}<.01 ; \mathrm{t}=6.1$, Student's t-test). Although the possibility that stridulatory signals might be involved could not be ruled out, the results of these experiments suggest that chemical cues are involved in the attraction 
response. Subsequently, crushes of the head, thorax, and gaster were offered on applicator stick tips at the nest entrance. Also, crushes of dissected poison and pygidial glands (Hölldobler and Engel, 1979) were offered. Only head crushes produced attraction. Whelden's (1958) studies, in addition to our own histological investigations, revealed a group of large glandular cells at the base of the mandible. The indirect evidence described above suggests that during prey capture the contents of these cells are released, attracting workers in the vicinity to assist in subduing prey.

3. Ecology and social evolution

The results of this study and previous investigations suggest that populations of $A$. pallipes are unicolonial. Workers from different subnests within a population show no aggression toward each other. Such worker compatibility has been demonstrated in Rhytidoponera metallica (Haskins and Haskins, 1979), whose populations appear to be structurally similar to those of $A$. pallipes, but occupy larger area geographically. Workers taken from nests three miles apart were not mutually hostile. The lack of aggression was consistent within, but not between populations. Ambylopone pallipes colonies appear to be similarly viscous, but do not occupy as extensive an area.

Observations in the laboratory are in accord with Brown's (1960) position which states that after mating, females "always or usually return to the parent nest". Secondary polygyny in this species, in addition to its patchy distribution, indicates that this species is in the terminology of Hölldobler and Wilson (1977) a habitat specialist. The characteristic $A$. pallipes habitat is cool, damp, heavily shaded woodland. Nest site and prey abundance are also important features. Populations apparently grow slowly, and through reproduction by budding, eventually saturate the habitat. Such a scheme does not rule out the occurrence of dispersal flights, which have been witnessed on occasion (Haskins, 1928). As colonies become more populous within a habitat, dispersal flights should occur more frequently in order to colonize additional areas. Once a founding queen locates a preferred habitat, colony reproduction again is accomplished through budding. The strategy may be similar to that of the mound building species Formica exsectoides. However, it must be noted that in laboratory situations, $A$. pallipes queens have never been observed to successfully found colonies (Haskins, per- 
sonal communication). But it is difficult to determine whether this is an abnormality which occurs only in the laboratory or represents an inability of $A$. pallipes queens to found a colony alone. Newly inseminated queens of $A$. australis found colonies in the partially claustral mode (Haskins and Haskins, 1951). However, A. australis is monogynous.

Within a habitat, $A$. pallipes escapes competition with the more advanced groups of ants by additional specializations on microhabitat and diet. This is in contrast to other unicolonial species which are broad generalists.

Behaviorally, A. pallipes exhibits both primitive and advanced social traits, and many of the primitive characters are more conservative than those of Myrmecia. Age polyethism is lacking, and communication between individuals is primarily mechanical, although a rudimentary short-range recruitment system that is mediated by pheremones exists. Among the primitive trophic characteristics is the use of the sting to paralyze prey, which are subsequently fed directly to the larvae without prior dismemberment. Employing the sting to paralyze prey appears to be widespread in the Ponerinae, and recently Maschwitz et al. (1979) have demonstrated that the venom of the oriental ponerine species Harpegnathus saltatus and Leptogenys chinensis indeed has paralytic, and not toxic, effects. Prey paralyzation also occurs in Daceton armigerum and Paltothyreus tarsatus (Wilson, 1962; Hölldobler, pers. comm.). This is contrasted to myrmicine species which use the sting as a defensive weapon. The importance of paralyzing but not killing arthropod prey in Amblyopone pallipes is obviously related to the direct provisioning of larvae; prey must be kept from decomposing until they are consumed. Also, immobilization is necessary for successful retrieval, and energetically it is more efficient for solitary foragers to carry paralyzed prey. The absence of regurgitation which is characteristic of the Ponerinae, also is a primitive trait. Although one of the more distinctive features of $A$. pallipes and other Amblyoponini, prey specialization, appears to be a conservative formicid trait, it is also possible that specialization was a response to competition.

Finally, based on the theories of Malyshev (1968), Wilson (1971) has speculated that the Amblyoponini may have approached eusociality in a way very different from the partially claustral colony founding route assumed by Haskins and Haskins (1951). Because 
these ants appear to be specialized on large arthropods, they may have passed through a phase of subsociality similar to that of the bethylid wasp Scleroderma. Although the evolution of ants from Scleroderma-like ancestors has been ruled out on morphological grounds, the possibility remains that the Amblyoponini represent an independent venture into eusociality. The present study, which suggests that $A$. pallipes is not dependent upon large arthropod prey, and the studies of Haskins (1928) and Haskins and Haskins (1951) on colony foundation, do not support or refute this theory. Additional studies must be carried out on the behavior of newly inseminated females, their prey preferences during colony foundation and their reproductive physiology to test this hypothesis.

\section{ACKNOWLEDGEMENTS}

This research was carried out while the author was a doctoral candidate at Harvard University, and was supported by the Anderson and Richmond Funds, NSF Grant BNS 80-02613 (B. Hölldobler, sponsor), and NSF predoctoral grant DEB 78-16201. Drs. Gary Alpert, Bert Hölldobler, and Edward Wilson provided useful comments on the manuscript. I would especially like to thank Dr. Caryl Haskins for sharing with me his great wealth of knowledge of primitive ants. Finally, I thank Michelle and Eric Scott, who were indispensable in the field.

\section{SUMMARY}

1. The behavior of ecology of the primitive ponerine ant Amblyopone pallipes was studied in the laboratory and the field. Thirtythree colonies were collected over a two-year period, $94 \%$ of which were excavated from one locality where $68 \%$ of the colonies were strongly clumped in their spatial distribution. Workers and queens could be transferred between these nests without hostility.

2. The inability of workers to recognize members of other colonies within a population, the colony life cycle, limited dispersal, the presence of multiple queens in nests, and circumstantial evidence on the adoption of newly inseminated females by their parent nest suggest that $A$. pallipes is secondarily polygynous and unicolonial. Although dispersal flights do occur, colony reproduction seems to be accomplished through budding. 
3. Studies on the ethology of $A$. pallipes show that this species has retained many conservative behavioral traits. Among these are the absence of age polyethism and the provisioning of larvae with whole prey (chiefly chilopods and beetle larvae). Observations of predatory behavior do not support the hypothesis that colonies are nomadic. Prey are paralyzed by stinging and are then retrieved. Larvae feed directly on the body of the prey.

4. A primitive form of alarm communication, presumably transmitted through body contact, is mediated by a vibratory display. Workers show attraction to head crushes, and mandibular gland pheromones appear to be involved in a weak form of recruitment.

5. Because of the lack of precise information on the behavior of colony founding queens, the question of whether sociality in the Amblyoponini arose in a manner different from the partially claustral colony founding mode of Myrmecia remains an enigma.

\section{REFERENCES}

Baroni Urbani C., 1978. - Contributo alla conoscenza del genere Amblyopone Erichson (Hymenoptera: Formicidae). Bull. Soc. Entomol. Suisse, 51, 39-51.

Brown W. L., 1960. - Contributions toward a reclassification of the Formicidae. III. Tribe Amblyoponini (Hymenoptera). Bull. Mus. Comp. Zool. Harvard, 122(4), $230 \mathrm{pp}$.

FAGEN R. M., Goldman R. N., 1977. - Behavioral catalogue analysis methods. Anim. Behav., 25, 261-274.

Francoevr A., 1965. - Écologie des populations de fourmis dans un bois de chênes rouges et d'érables rouges. Nat. Canadien, 92, 263-276.

Francoevr A., 1979. - Les fourmis du Québec. Ann. Soc. Entomol. Québec, 24, 12-47.

Gotwald W. H., Lévieux J., 1972. - Taxonomy and biology of a new west African ant belonging to the genus Amblyopone. Ann. Entomol. Soc. Amer., 65, 383-396.

Haskins C. P., 1928. - Notes on the behavior and habits of Stigmatomma pallipes Haldeman. J. New York Entomol. Soc., 36, 179-184.

Haskins C. P., 1979. - Sexual calling behavior in highly primitive ants. Psyche, $85,407-416$.

Haskins C. P., Enzmann E. V., 1938. - Studies of certain sociological and physiological features in the Formicidae. Ann. New York Acad. Sci., 37, 97-162.

79. - Worker compatibilities within and between populations of Rhytidoponera metallica. Psyche 86, 301-312.

Hölldobler B. K., 1977. - Communication in social Hymenoptera. In Sebeok T., ed., How Animals Communicate. Indiana Univ. Press, Bloomington, Indiana, pp. 418-471.

Hölldobler B. K., Engel H., 1979. - Tergal and sternal glands in ants. Psy'che, 
$85,285-330$.

HöLldobler B. K., Wilson E. O., 1977. - The number of queens: an important trait in ant evolution. Naturwissenschaften, 64, 8-15.

Malyshev S. I., 1968. - Genesis of the Hymenoptera and the phases of their evolution (tr. from Russian by B. Haigh; Richards O. W., Uvarov B., eds.). Methuen and Co., London. viii +319 pp.

Maschwitz U., Hahn M., Schöenegge P., 1979. - Paralysis of prey in ponerine ants. Naturwissenschaften, 66, 213.

TаLвот M., 1957. - Populations of ants in a Missouri woodland. Ins. Soc., 4, 375-384.

Traniello J. F. A., 1978. - Caste in a primitive ant: absence of age polyethism in Amblyopone. Science, 202, 770-772.

Wheeler W. M., 1900. - The habits of Ponera and Stigmatomma. Biol. Bull., 2, 43-69.

WILSON E. O., 1958. - The beginnings of nomadic and group-predatory behavior in the ponerine ants. Evolution, 12, 24-31.

WiLSON E. O., 1962. - Behavior of Daceton armigerum (Latreille), with a classification of self-grooming movements in ants. Bull. Mus. Comp. Zool. Harvard, 127, 403-421.

WiLson E. O., 1971. - The Insect Societies. Belknap Press of Harvard Univ. Press, Cambridge, Mass. 548 pp.

WiLson E. O., 1975. - A social ethogram of the Neotropical arboreal ant Zacryptocerus varians (Fr. Smith). Anim. Behav., 24, 354-363. 

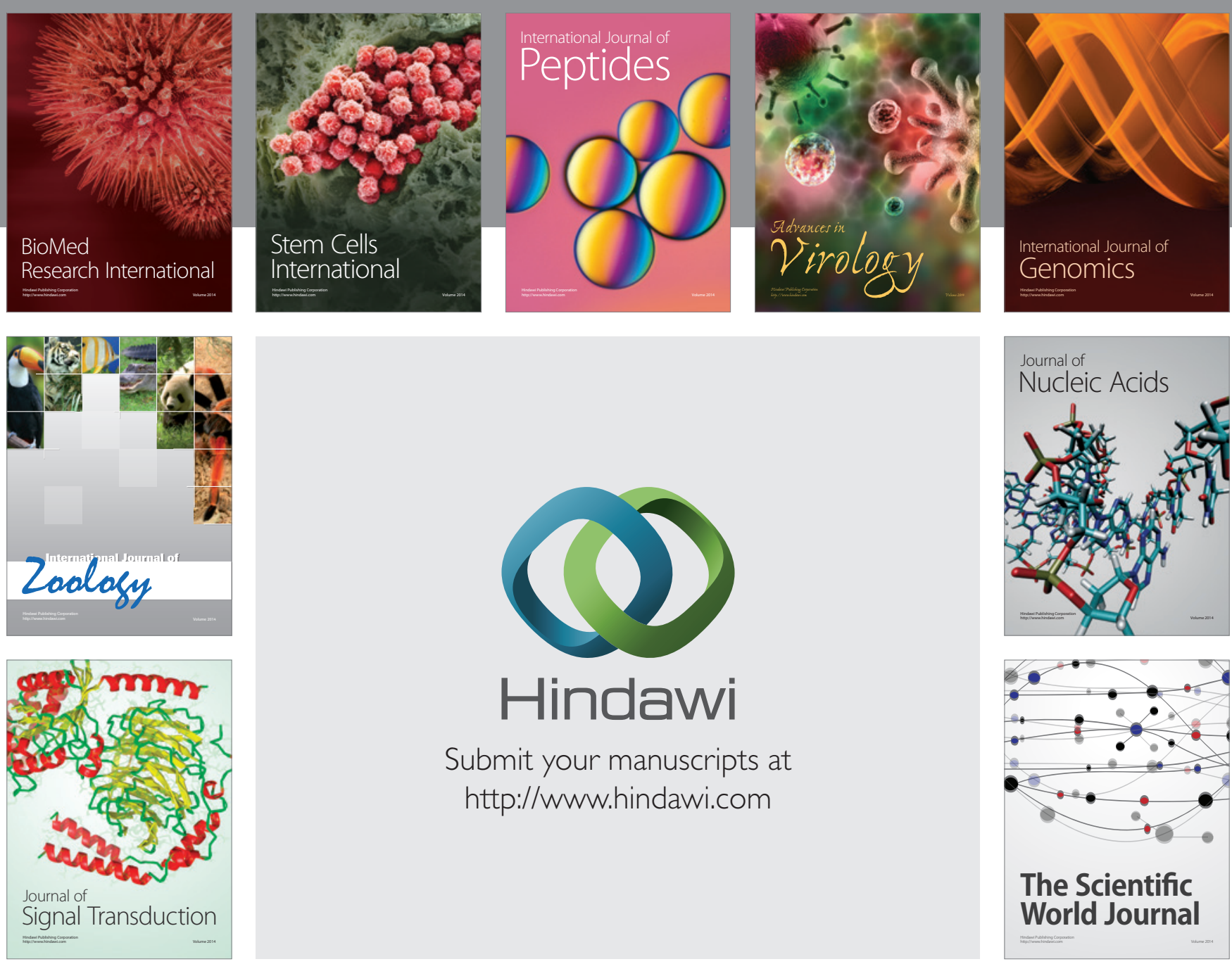

Submit your manuscripts at

http://www.hindawi.com
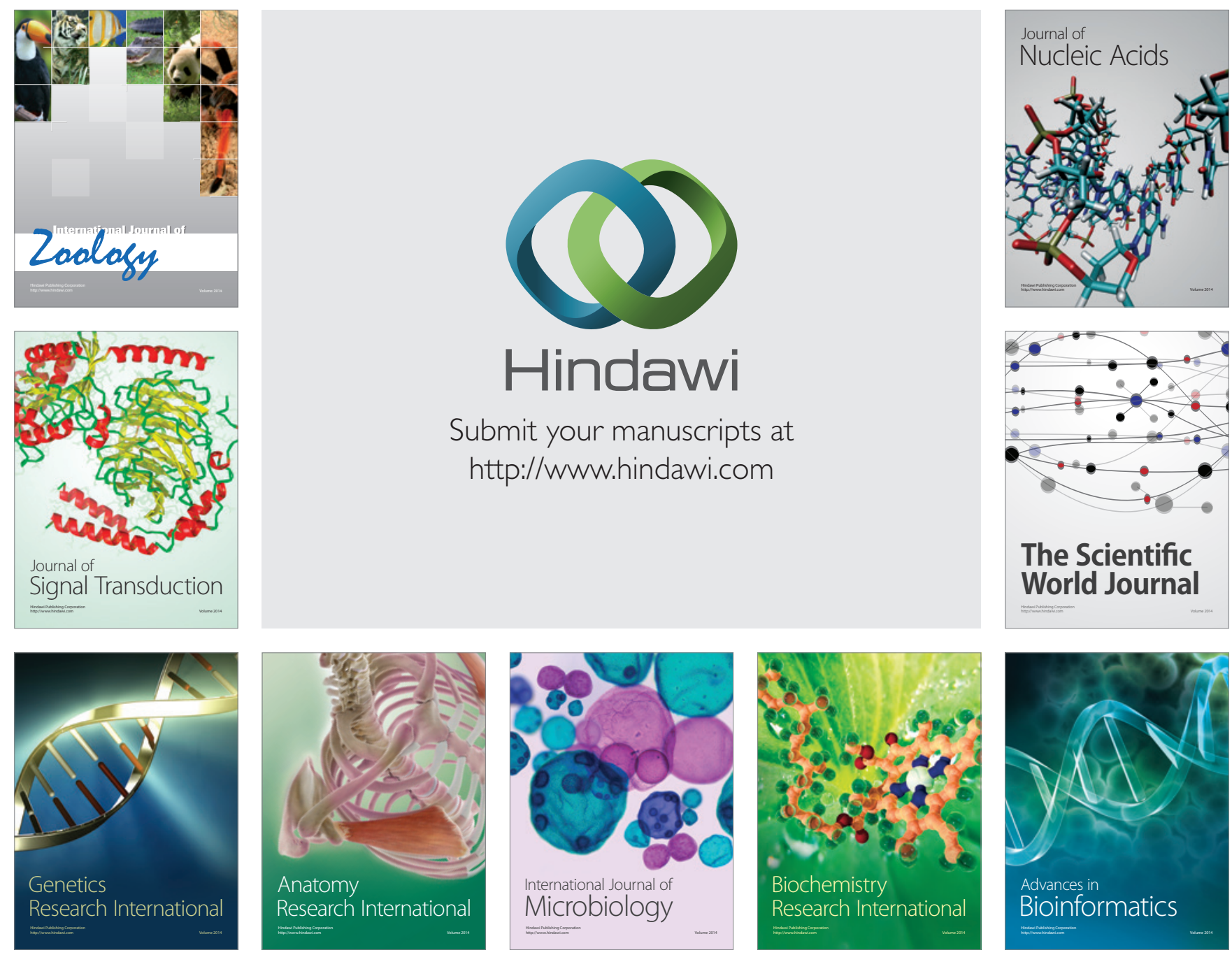

The Scientific World Journal
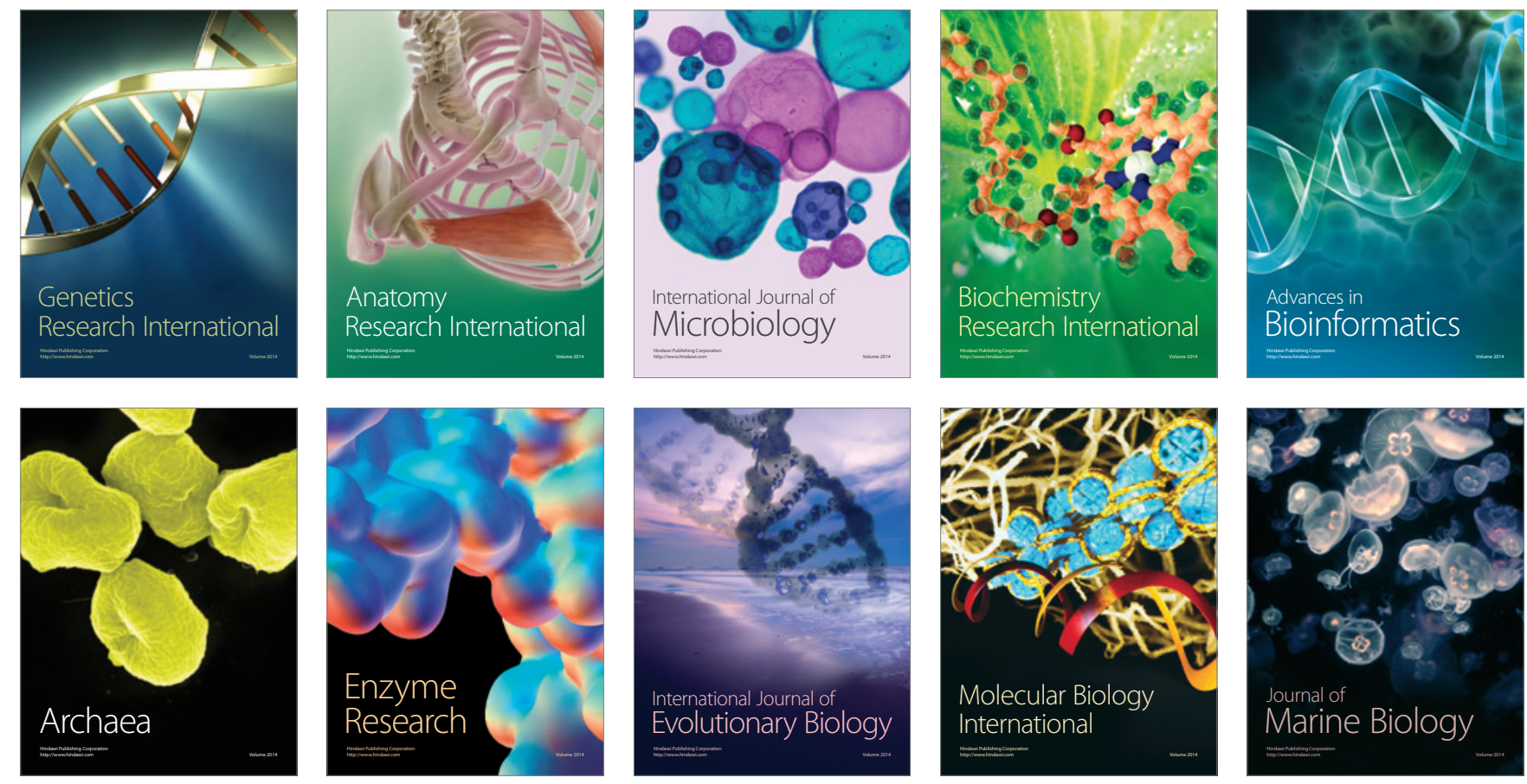